\title{
OBSERVAÇÃO DOS SEDIMENTOS DE FUNDO DE UMA PLATAFORMA ABRIGADA SOB INFLUÊNCIA DE ATIVIDADE DE DRAGAGEM: SACO DOS LIMÕES, FLORIANÓPOLIS, SC
}

\author{
SCHETTINI, C.A.F; SANTOS, M.I.F. \& J.G.N. de ABREU \\ Centro de Tecnologia da Terra e do Mar - CTTMar/UNIVALI \\ CX.P. 360 - Itajaí - SC - CEP 88302.202 - Brasil
}

\begin{abstract}
RESUMO
Este artigo apresenta uma avaliação da distribuição faciológica dos sedimentos de fundo do Saco dos Limões e da região norte da Baía Sul, Florianópolis. Os levantamentos foram realizados durante a operação de dragagem que estava sendo realizada no saco para o alargamento da orla leste para implementação da Via Expressa SC-Sul.
\end{abstract}

Palavras chave: sedimentologia marinha; faciologia; Saco dos Limões.

\section{OBSERVATION OF BOTTOM SEDIMENTS IN A SHELTERED SHELF UNDER DREDGING ACTIVITY: SACO DOS LIMÕES, FLORIANÓPOLIS, SC}

\begin{abstract}
This article presents an assessment on the faciologic distribution of bottom sediments in the Saco dos Limões and the northern region of the Baía Sul, Florianópolis. The samples were surveyed during the dredging operations which were been carried out aiming the enlargement of the east shore of the bay to implementation of the Via Expressa SC-Sul.
\end{abstract}

Keywords: marine sedimentology; faciology; Saco dos Limões.

\section{INTRODUÇÃO}

O Saco dos Limões é uma enseada rasa localizada no interior da Baía Sul, Florianópolis (Figura 1), que em função do crescimento urbano e do relevo acidentado da capital catarinense, teve sua porção marginal aterrada para implementação de um projeto viário. Os sedimentos arenosos necessários para o aterro hidráulico foram retirados de jazidas localizadas na própria enseada, através de dragas de sucção e recalque, sendo despejados ao longo da margem leste.

Durante o período de dragagens foram monitorados diversos parâmetros físicos, quí- micos, geológicos e biológicos da enseada, com o objetivo de avaliar os impactos sobre o meio ambiente. No Saco dos Limões está localizada a Reserva Extrativista Marinha de Pirajubaé, onde se desenvolve a atividade de coleta de berbigões (Annomalocardia brasiliana) por pescadores artesanais locais, e na sua margem sul está localizado o Manguezal do Rio Tavares, mostrando assim a importância da preservação deste sistema.

Os diversos impactos advindos da atividade de dragagem em corpos de água costeiros podem ser caracterizados em escalas locais $\left(10^{2} \mathrm{~m}\right)$ ou não locais $\left(10^{3}-10^{4} \mathrm{~m}\right)$, em escalas de tempo curtas (dias) ou longas (me- 
ses a anos). O incremento da concentração de sedimentos em suspensão é considerado um efeito local em escala de tempo curta (IADC, 1997), porém a remobilização de sedimentos finos consolidados podem gerar impactos mais profundos que necessitarão de um maior período de tempo para serem assimilados pelo ambiente, o que pode levar até décadas.

O presente trabalho apresenta resultados da distribuição faciológica dos sedimentos de fundo do Saco dos Limões durante o período que estava sendo realizada a dragagem, discutindo os efeitos da atividade de dragagem sobre a mudança da qualidade dos sedimentos.

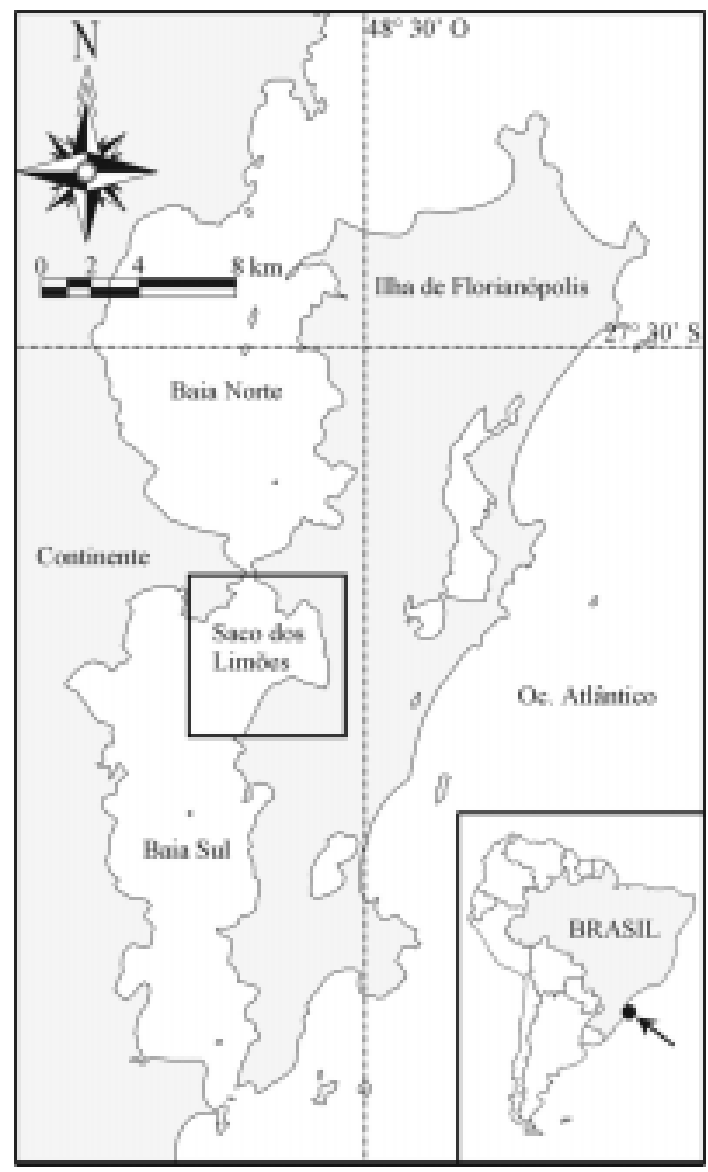

Figura 1: Localização da área de estudo.

\section{ÁREA DE ESTUDO}

O Saco dos Limões é uma enseada de aproximadamente $7 \mathrm{~km}^{2}$, apresentando-se bastante rasa, com profundidades inferiores à $1 \mathrm{~m}$ na sua porção sul, e um pouco mais profunda na porção norte (Figura 2). Existe um fosso na região central devido à atividades de dragagem passadas, denominado de 'buraco da draga', e foi aumentado com a dragagem realizada em 1996 e 1997. Afastando-se da enseada em direção ao centro da baia, à oeste, ocorre um talude onde as profundidades são superiores a 3 metros. Ao norte, na região do estreito entre as baías Norte e Sul, as profundidades são superiores a $10 \mathrm{~m}$. A Figura 2A apresenta um bloco diagrama representando a batimetria do sistema.

A principal entrada fluvial no Saco dos Limões é o Rio Tavares, que deságua na porção sul à leste. Existem outros pequenos estuários que cortam o manguezal, com dimensões bem inferiores ao do Rio Tavares. Estes sistemas apresentam complicados padrões hidrodinâmicos decorrente da presença de seiches no sistema de baías. Observações no balanço de massa no estuário do Rio Tavares e no estuário do Rio dos Defuntos apontaram que o primeiro exporta sedimentos para a região do saco, ao passo que o segundo atua como importador. O mesmo deve se dar com os demais sistemas pequenos (Schettini et al., 2000). Excluindo-se a porção sul onde localiza-se o Manguezal do Rio Tavares, as demais margens do Saco dos Limões são urbanizadas recebendo em muitos pontos aportes de sistemas de drenagem pluvial.

\section{MATERIAL \& MÉTODOS}

As 23 amostras de sedimento utilizadas neste trabalho foram coletadas nos dias $19 \mathrm{e}$ 21 de outubro de 1996, com um busca fundo do tipo PONAR. As coordenadas geográficas das estações foram obtidas com um receptor portátil de GPS (Tabela 1; Figura 2). Em labo- 

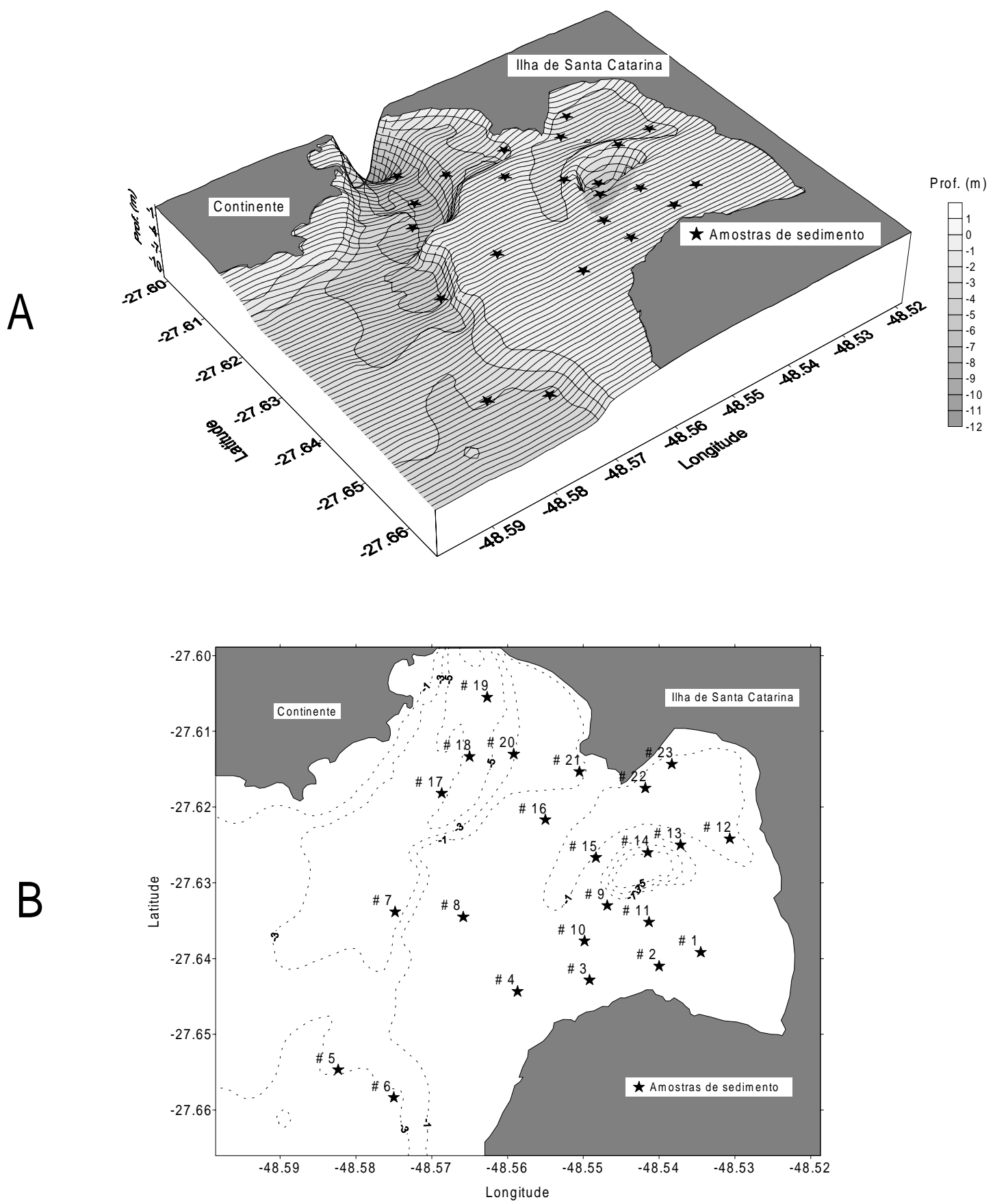

Figura 2: A: Bloco diagrama representado a batimetria do Saco dos Limões; e B: gráfico horizontal da batimetria e posicionamento das estações de coleta de sedimentos de fundo. 
Tabela 1: Posição das amostras de sedimento de fundo.

\begin{tabular}{c|c|c|c|c|c}
\hline \hline Estação & Longitude & Latitude & Estação & Longitude & Latitude \\
\hline 1 & $-48,535$ & $-27,639$ & 13 & $-48,537$ & $-27,625$ \\
2 & $-48,540$ & $-27,641$ & 14 & $-48,542$ & $-27,626$ \\
3 & $-48,549$ & $-27,643$ & 15 & $-48,548$ & $-27,627$ \\
4 & $-48,559$ & $-27,644$ & 16 & $-48,555$ & $-27,622$ \\
5 & $-48,582$ & $-27,655$ & 17 & $-48,569$ & $-27,618$ \\
6 & $-48,575$ & $-27,658$ & 18 & $-48,565$ & $-27,613$ \\
7 & $-48,575$ & $-27,634$ & 19 & $-48,563$ & $-27,606$ \\
8 & $-48,566$ & $-27,635$ & 20 & $-48,559$ & $-27,613$ \\
9 & $-48,547$ & $-27,633$ & 21 & $-48,551$ & $-27,615$ \\
10 & $-48,550$ & $-27,638$ & 22 & $-48,542$ & $-27,618$ \\
11 & $-48,541$ & $-27,635$ & 23 & $-48,538$ & $-27,614$ \\
12 & $-48,531$ & $-27,624$ & - & - & - \\
\hline \hline
\end{tabular}

ratório, as amostras foram lavadas para eliminação de sais, secas em estufa e quarteadas. A análise granulométrica foi realizada segundo os métodos tradicionais de peneiramento para sedimentos grosseiros (>0,062 $\mathrm{mm}$ ) com intervalo de $1 / 2$ phi, e pipetagem para sedimentos mais finos. Não foi extraído das amostras o conteúdo de matéria orgânica nem de carbonatos.

Os parâmetros estatísticos foram determinados pelo método do momento de distribuição (Lindholm, 1987), através de rotina em ambiente computacional Matlab ${ }^{\mathrm{TM}}$ (Anexo 1). Os gráficos de distribuição de propriedades foram gerados através do programa para computadores Surfer, versão 6.0, para ambiente Windows 95. Foi utilizado o método Kriging de interpolação.

\section{RESULTADOS}

Os fracionamento granulométrico de todas as amostras de sedimento são apresentados na Tabela 2.

Os sedimentos de fundo do Saco dos Limões apresentam-se bastante distintos em duas classes predominantes de acordo com a nomenclatura proposta por Shepard (1954). Uma classe consiste de sedimentos argilosos e sílticos argilosos, e outra de sedimentos arenosos e síltico arenosos (Figura 3). Esta dife- renciação de classes apresenta uma clara correspondência com a distribuição geográfica dos sedimentos (Figura 4). As amostras de sedimento com predominância da fração fina estão localizadas na região mais interior da enseada e para norte e noroeste, onde se observa as maiores profundidades. Por outro lado, as amostras com predominância de sedimentos arenosos estão localizadas nos baixios próximos do Manguezal do Rio Tavares e para sudoeste. A distribuição dos sedimentos arenosos coincide razoavelmente com a distribuição de grânulos, que nestes caso são de origem biodetrítica. No entanto é interessante notar que a amostra \# 15 apresentou um teor superior à $15 \%$ de biodetritos, e está localizada na denominada 'alça do buraco da draga'.

A distribuição dos parâmetros estatísticos reflete a distribuição faciológica (Figura 5), porém de maneira diferenciada em relação à distribuição dos teores de diferentes classes. A distribuição do tamanho médio, desvio padrão e variância apresentaram distribuições semelhantes, com uma forte correspondência com a distribuição espacial do teor de grânulos. A distribuição da razão desvio padrão:média, assimetria e kurtosis apresentaram distribuições correspondentes com as distribuições de silte e argila.

Os valores dos momentos de distribuição superiores apresentaram valores extremamente altos, com a variância alcançando $2 \mathrm{~mm}$, 
NOTAS TÉC. FACIMAR, 6: 165-175, 2002.

Tabela 2: Resultado do fracionamento das amostras, em gramas.

\begin{tabular}{|c|c|c|c|c|c|c|c|c|c|c|c|c|}
\hline Phi & 1 & 2 & 3 & 4 & 5 & 6 & 7 & 8 & 9 & 10 & 11 & 12 \\
\hline$-2,0$ & 0,00 & 4,71 & 5,64 & 7,31 & 3,71 & 0,02 & 0,00 & 1,34 & 0,00 & 0,00 & 0,00 & 0,00 \\
\hline$-1,5$ & 0,00 & 0,30 & 0,34 & 1,24 & 3,63 & 0,04 & 0,00 & 2,85 & 0,24 & 0,15 & 0,00 & 0,00 \\
\hline$-1,0$ & 0,00 & 0,14 & 0,26 & 1,49 & 2,20 & 0,10 & 0,07 & 3,20 & 0,20 & 0,22 & 0,00 & 0,00 \\
\hline$-0,5$ & 0,04 & 0,21 & 0,25 & 1,22 & 1,68 & 0,18 & 0,05 & 3,08 & 0,28 & 0,17 & 0,00 & 0,00 \\
\hline 0,0 & 0,02 & 0,14 & 0,19 & 1,25 & 0,84 & 0,32 & 0,03 & 2,15 & 0,22 & 0,20 & 0,00 & 0,00 \\
\hline 0,5 & 0,03 & 0,19 & 0,22 & 1,26 & 0,68 & 0,44 & 0,04 & 1,35 & 0,33 & 0,23 & 0,00 & 0,00 \\
\hline 1,0 & 0,02 & 0,15 & 0,16 & 1,51 & 0,39 & 0,66 & 0,03 & 1,58 & 0,25 & 0,38 & 0,00 & 0,00 \\
\hline 1,5 & 0,04 & 0,43 & 0,50 & 2,20 & 0,90 & 1,62 & 0,13 & 1,65 & 1,19 & 0,79 & 0,00 & 0,01 \\
\hline 2,0 & 0,10 & 2,55 & 2,89 & 6,23 & 3,70 & 19,16 & 1,14 & 4,04 & 6,37 & 4,33 & 0,01 & 0,02 \\
\hline 2,5 & 0,49 & 12,10 & 15,67 & 11,54 & 7,33 & 17,69 & 5,62 & 6,08 & 19,66 & 16,95 & 0,12 & 0,08 \\
\hline 3,0 & 1,48 & 8,69 & 13,59 & 16,59 & 9,36 & 0,25 & 7,87 & 12,23 & 10,34 & 14,62 & 1,50 & 0,26 \\
\hline 3,5 & 0,46 & 1,46 & 2,75 & 2,93 & 0,88 & 0,03 & 0,10 & 0,79 & 0,23 & 1,47 & 1,67 & 0,16 \\
\hline 4,0 & 0,20 & 0,24 & 0,29 & 0,98 & 0,05 & 0,01 & 1,19 & 0,01 & 0,33 & 0,04 & 0,68 & 0,09 \\
\hline 5,0 & 3,56 & 0,87 & 0,45 & 0,13 & 0,00 & 0,01 & 0,90 & 0,00 & 0,00 & 0,02 & 4,22 & 3,48 \\
\hline 6,0 & 2,58 & 0,51 & 0,32 & 0,00 & 0,00 & 0,00 & 1,04 & 0,00 & 0,00 & 0,00 & 2,53 & 1,73 \\
\hline 7,0 & 4,70 & 0,78 & 0,29 & 0,00 & 0,00 & 0,00 & 2,53 & 0,00 & 0,00 & 0,00 & 2,54 & 3,33 \\
\hline 8,0 & 3,39 & 1,00 & 0,74 & 0,00 & 0,00 & 0,00 & 2,72 & 0,00 & 0,00 & 0,00 & 2,41 & 4,96 \\
\hline 9,0 & 2,29 & 0,39 & 0,10 & 0,00 & 0,00 & 0,00 & 2,13 & 0,00 & 0,00 & 0,00 & 1,28 & 2,24 \\
\hline 10,0 & 1,27 & 0,49 & 0,74 & 0,00 & 0,00 & 0,00 & 0,88 & 0,00 & 0,00 & 0,00 & 2,28 & 1,96 \\
\hline 11,0 & 2,36 & 0,69 & 0,64 & 0,00 & 0,00 & 0,00 & 1,85 & 0,00 & 0,00 & 0,00 & 1,25 & 2,70 \\
\hline 12,0 & 16,98 & 4,78 & 2,99 & 0,00 & 0,00 & 0,00 & 11,99 & 0,00 & 0,00 & 0,00 & 19,77 & 19,05 \\
\hline Total & 40,02 & 40,79 & 48,99 & 55,87 & 35,34 & 40,54 & 40,26 & 40,34 & 39,63 & 39,58 & 40,24 & 40,05 \\
\hline Phi & 13 & 14 & 15 & 16 & 17 & 18 & 19 & 20 & 21 & 22 & 23 & \\
\hline$-2,0$ & 0,00 & 0,66 & 9,63 & 0,00 & 0,00 & 0,00 & 0,00 & 0,00 & 0,00 & 0,00 & 0,00 & \\
\hline$-1,5$ & 0,00 & 1,31 & 2,22 & 0,04 & 0,00 & 0,00 & 0,00 & 0,00 & 0,00 & 0,00 & 0,00 & \\
\hline$-1,0$ & 0,00 & 1,42 & 1,32 & 0,02 & 0,00 & 0,01 & 0,00 & 0,00 & 0,00 & 0,00 & 0,00 & \\
\hline$-0,5$ & 0,00 & 1,95 & 1,28 & 0,04 & 0,00 & 0,01 & 0,00 & 0,00 & 0,00 & 0,00 & 0,00 & \\
\hline 0,0 & 0,00 & 1,45 & 0,73 & 0,03 & 0,00 & 0,01 & 0,00 & 0,00 & 0,00 & 0,00 & 0,00 & \\
\hline 0,5 & 0,00 & 1,97 & 0,72 & 0,02 & 0,00 & 0,01 & 0,00 & 0,00 & 0,00 & 0,00 & 0,00 & \\
\hline 1,0 & 0,00 & 1,08 & 0,39 & 0,01 & 0,00 & 0,02 & 0,00 & 0,00 & 0,00 & 0,00 & 0,00 & \\
\hline 1,5 & 0,00 & 1,00 & 0,45 & 0,02 & 0,00 & 0,03 & 0,01 & 0,01 & 0,00 & 0,00 & 0,00 & \\
\hline 2,0 & 0,00 & 1,28 & 1,26 & 0,01 & 0,01 & 0,05 & 0,02 & 0,01 & 0,02 & 0,01 & 0,00 & \\
\hline 2,5 & 0,02 & 4,70 & 7,24 & 0,05 & 0,02 & 0,16 & 0,08 & 0,02 & 0,18 & 0,02 & 0,01 & \\
\hline 3,0 & 0,09 & 6,66 & 12,43 & 0,14 & 0,10 & 0,31 & 0,17 & 0,08 & 0,99 & 0,14 & 0,05 & \\
\hline 3,5 & 0,36 & 1,00 & 1,57 & 0,11 & 0,17 & 0,20 & 0,15 & 0,31 & 0,71 & 0,20 & 0,05 & \\
\hline 4,0 & 0,36 & 0,14 & 1,24 & 0,09 & 0,27 & 0,11 & 0,08 & 0,25 & 0,08 & 0,11 & 0,04 & \\
\hline 5,0 & 5,06 & 0,36 & 0,60 & 2,73 & 3,16 & 2,30 & 3,02 & 2,11 & 2,22 & 2,72 & 1,94 & \\
\hline 6,0 & 3,57 & 0,32 & 0,68 & 1,71 & 2,59 & 1,93 & 1,57 & 2,08 & 1,84 & 1,03 & 2,52 & \\
\hline 7,0 & 4,02 & 1,35 & 0,91 & 3,48 & 3,70 & 2,79 & 4,20 & 3,13 & 2,47 & 4,47 & 1,75 & \\
\hline 8,0 & 4,36 & 1,74 & 1,01 & 4,64 & 4,30 & 4,96 & 3,95 & 5,04 & 4,80 & 4,30 & 4,23 & \\
\hline 9,0 & 0,29 & 0,82 & 0,45 & 2,24 & 2,81 & 2,86 & 2,55 & 2,53 & 2,40 & 2,50 & 1,65 & \\
\hline 10,0 & 4,10 & 0,97 & 2,29 & 2,36 & 1,43 & 1,69 & 2,19 & 1,55 & 1,64 & 2,08 & 2,09 & \\
\hline 11,0 & 0,42 & 1,20 & 0,82 & 1,86 & 2,04 & 2,41 & 1,75 & 2,87 & 2,86 & 2,44 & 3,08 & \\
\hline 12,0 & 17,39 & 8,63 & 2,74 & 20,57 & 19,42 & 20,19 & 20,40 & 20,08 & 19,83 & 20,05 & 22,62 & \\
\hline Total & 40,01 & 40,01 & 49,98 & 40,19 & 40,01 & 40,00 & 40,15 & 40,07 & 40,01 & 40,04 & 40,02 & \\
\hline
\end{tabular}




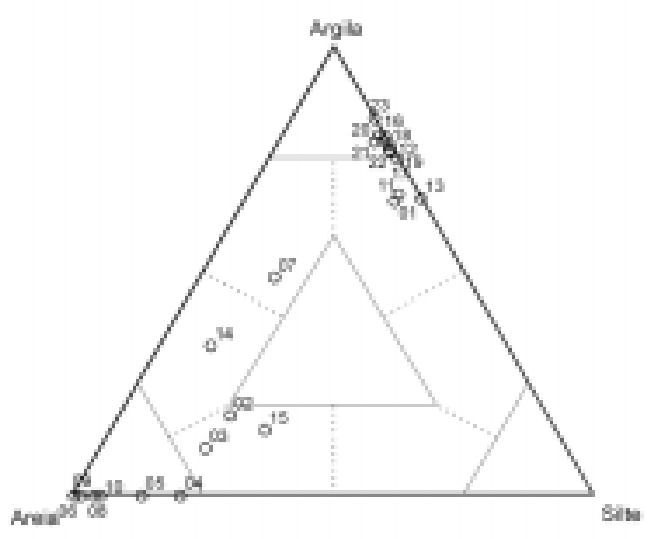

Figura 3: Diagrama de Shepard com a localização das amostras de sedimento de fundo do Saco dos Limões. a assimetria $28 \mathrm{~mm}$ e a kurtosis $1.000 \mathrm{~mm}$, refletindo curvas de distribuição bastante distorcidas em comparação a uma curva de distribuição gaussiana normal, como pode ser observado na distribuição de freqüência acumulada (Figura 6).

\section{DISCUSSÃO}

A distribuição de sedimentos de fundo em plataformas abrigadas é bastante variável de um sistema para outro. No entanto, podemos generalizar uma distribuição hipotética em função dos níveis de energia ao que os sedimentos estão suscetíveis. Em função da ação de ondas locais de alta freqüência, é esperado que ocorra a ressuspensão dos sedimentos fi-
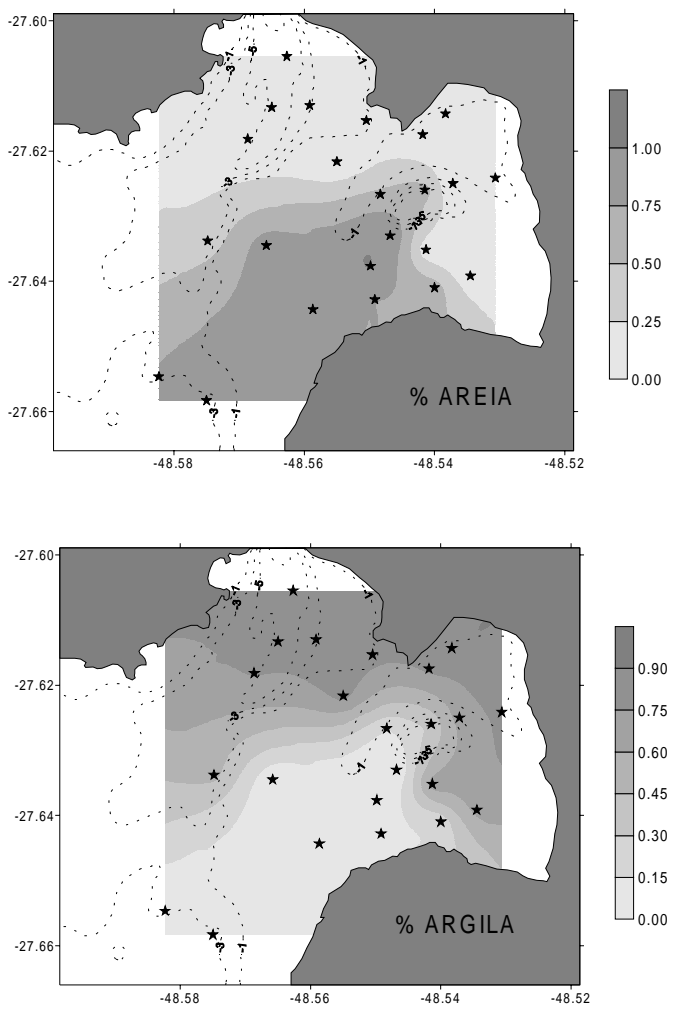

Figura 4: Distribuição espacial das frações de grânulo, areia, silte e argila no Saco dos Limões. 
Média

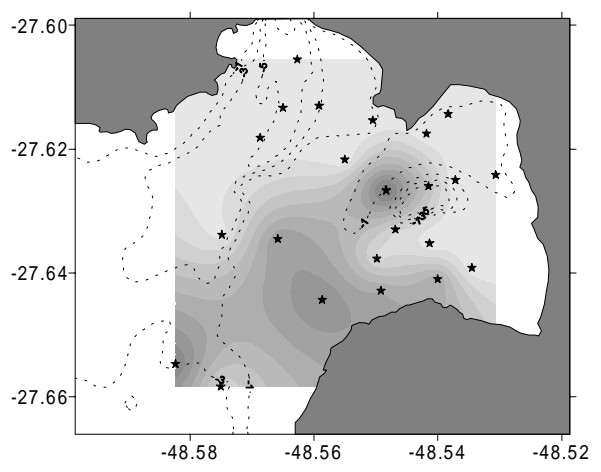

Desvio padrão / Média

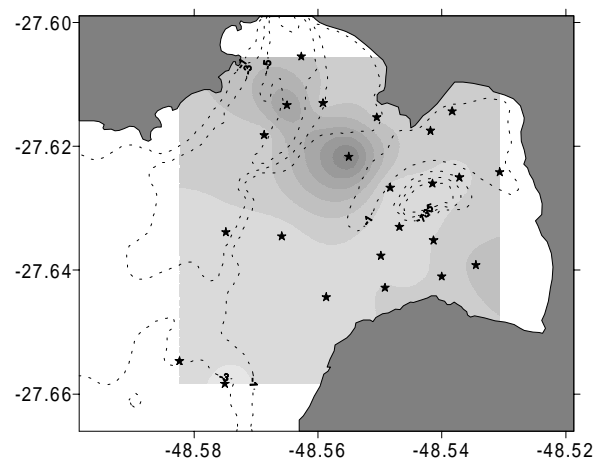

Assimetria

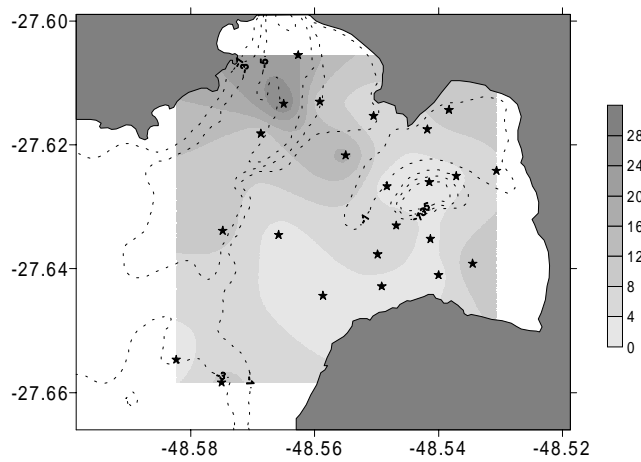

Desvio padrão

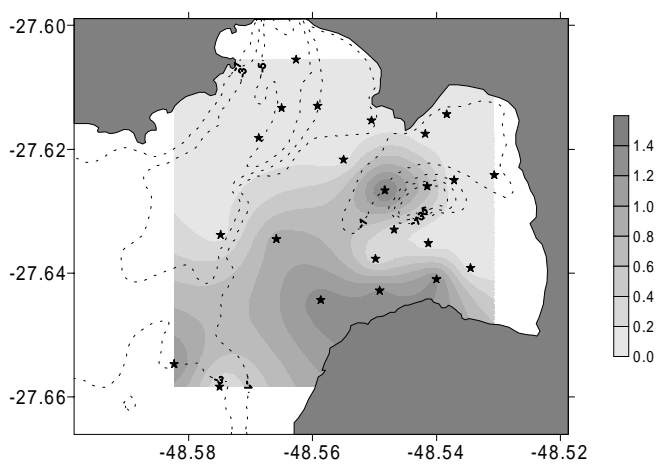

Variância

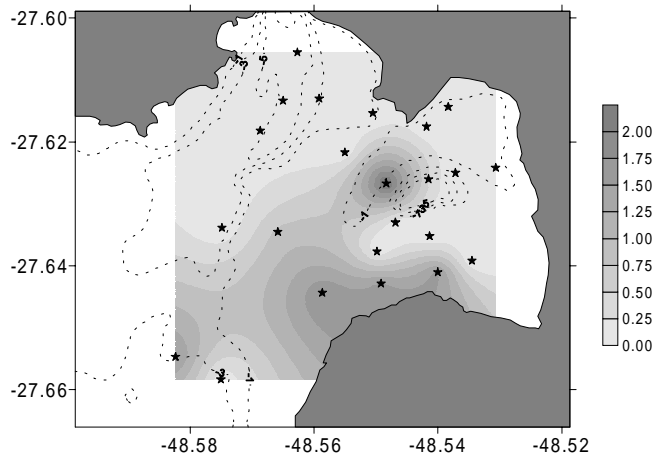

\section{Kurtosis}

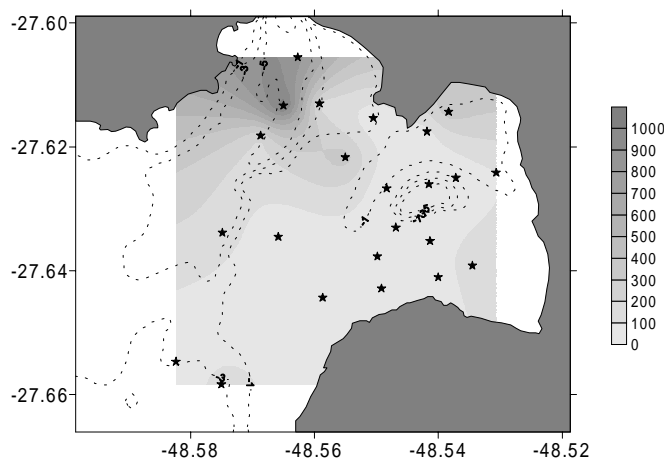

Figura 5: Distribuição dos parâmetros estatísticos: média, desvio padrão, razão desvio padrão:média, variância, assimetria e kurtosis, dos sedimentos de fundo do Saco dos Limões. 


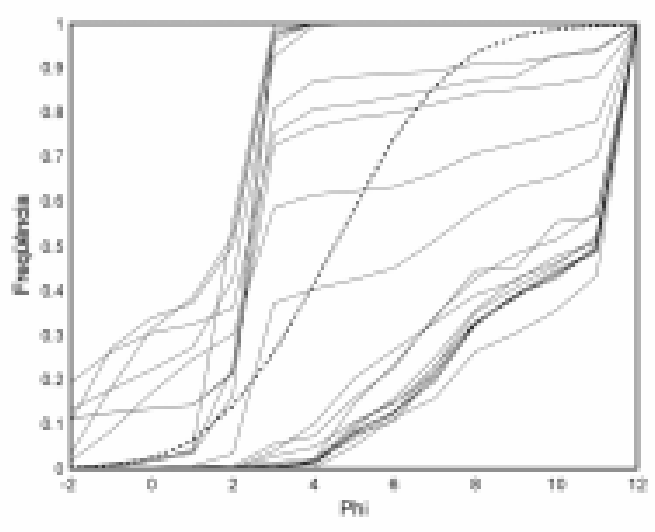

Figura 6: Distribuição de freqüência acumulada das amostras de sedimento de fundo do Saco dos Limões. A linha tracejada representa uma distribuição gaussiana normal.

nos na regiões mais rasas, sendo estes transportados até locais com menor energia nas regiões mais profundas. Ao longo do tempo, em reposta das condições energéticas normais, espera-se encontrar um gradiente de sedimentos arenosos nas porções rasas para sedimentos finos nas regiões mais profundas, e também uma razoável seleção granulométrica. Contudo, considerando-se também os efeitos de correntes de marés, caso estas sejam mais importantes que à ação de ondas, a propagação desta em águas rasas gera assimetria no regime de correntes que podem por sua vez acumular sedimentos finos na zona intermareal (Dyer, 1986), formando por exemplo o plano de maré observado defronte ao manguezal.

O que se observa no Saco dos Limões, entretanto, é uma distribuição de sedimentos de fundo bastante distorcida em relação ao que se é esperado. Embora não existam informações pretéritas para comparações, aparentemente a atividade de dragagem desempenhou um papel importante nas distribuições de frações de sedimento e, em conseqüência, dos parâmetros estatísticos encontrados. Um outro problema associado com a distorção das distribuições de freqüência foi a não retirada dos carbonatos, que para este caso são de origem biodetrítica autôctona a partir dos bancos de berbigões existentes na enseada.

A razão de variação desvio padrão:média apresentou valores extremamente altos, principalmente nas regiões com predominância de sedimentos finos, o que também ocorreu com a distribuição da assimetria e kurtosis. Uma interpretação possível para estes resultados seria a contaminação das regiões com predominância de sedimentos muito finos com areias finas remobilizadas e disponibilizadas pela atividade de dragagem. Isto acarretaria na elevação do valor médio, do desvio padrão, e consequentemente dos momentos de distribuição superiores de maneira exponencial.

Os parâmetros estatísticos não são úteis no presente caso para avaliar as características das distribuições de freqüência dos sedimentos de fundo, porém podem indicar o grau de alteração sofrido em função da atividade de dragagem que ocorreu na enseada. Com uma nova campanha de aquisição de amostras de sedimento de fundo será possível averiguar ser estes parâmetros retornaram para níveis 'normais', ou se os efeitos da dragagem ainda estão sendo sentidos.

\section{AGRADECIMENTOS}

Os autores agradecem ao Sr. Gentil Silvestre pelo processamento das amostras granulométricas. Este trabalho foi realizado com suporte financeiro do Departamento de Estradas e Rodagem - Santa Catarina (DER-SC), dentro do programa de monitoramento ambiental na área de abrangência das obras da Via Expressa SC-Sul, Florianópolis, SC.

\section{REFERÊNCIAS BIBLIOGRÁFICAS}

IADC 1997. Environmental aspects of dredging: investigation, interpretation and impacts. The Hague, IADC/CEDA, 67p. 
Dyer, K. 1986. Coastal and estuarine sediment dynamics. New York, John Wiley \& Sons, 342p.

Lindholm, R. 1987. A practical approach to sedimentology. London, Allen \& Unwin, 276p.

Schettini, C.A.F.; Pereira Filho, J. \& L. Spillere 2000. Caracterização oceanográfica e biogeoquímica dos estuários dos rio Tavares e dos Defuntos, Reserva Extrativista de Pirajubaé, Florianópolis, SC. Notas Téc. Facimar, 4:11-28.

Shepard, F.P. 1954. Nomenclature based on sand-silt-clay ratios. Journal of Sedimentary Petrology, 24(3):151-158. 
Anexo 1: Rotina para Matlab ${ }^{\mathrm{TM}} 5.0$ para determinação dos parâmetros de distribuição da amostra: média, desvio padrão, variância, assimetria e kurtosis.

\section{\% MFILE PARA FAZER ANÁLISE GRANULOMÉTRICA: ANGRA.M}

$\%$

$\%$ seguindo as equações descritas em Lindholm, 1987, e com os dados do \% exemplo da página 167.

$\%$

$\%$ Sintaxe:

$\%$

$\% \mathrm{x}=$ angra(tamanho de grão em $\mathrm{mm}$, massa retida na peneira)

$\%$

$\%$ Schettini, 24/jun/98

$\%$ Lindholm, R. 1987 A practical approach to sedimentology. London, $\%$ Allen \& Unwin, 276pp.

function saida=angra $(\mathrm{mm}$,data $)$

\%mm=[1.5 .75 .375 .1875 .0938 .031]; \% dados do exemplo

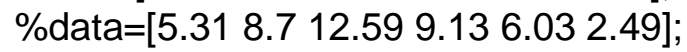

$\mathrm{n}=$ length(data);

media $=$ sum(data. $\left.{ }^{*} \mathrm{~mm}\right) /$ sum(data); $\quad \%$ acha a média

temp $=\mathrm{mm}-$ media;

ps=power(temp,2);

$\mathrm{pt}=$ power $($ temp,3);

pk=power(temp,4);

desvp $=\left(\right.$ sum(data. ${ }^{*}$ ps $) /$ sum $($ data $\left.)\right)^{\wedge} 0.5 ; \quad \%$ desvio padrão

varia $=\operatorname{sum}\left(\right.$ data. $\left.{ }^{*} \mathrm{ps}\right) /$ sum $($ data $)$;

\% variância

assim $=$ sum(data. ${ }^{*}$ pt)/sum(data);

$\%$ assimetria

kurts $=\operatorname{sum}\left(\right.$ data. ${ }^{*}$ pk $) /$ sum(data);

$\%$ kurtosis

$\operatorname{assim}=\operatorname{assim} / \operatorname{varia}^{\wedge}(3 / 2)$;

kurts = kurts $/$ varia^ 2 ;

saida $=$ [media desvp varia assim kurts]; 
Anexo 2: Rotina para Matlab 5.0 para desenhar e localizar amostras no diagrama de Shepard.

\% Mfile para diagrama para representar as frações de areia, silte e $\%$ argila, segundo Shepard, 1954: SHEPARD.M

$\%$

$\% \quad$ Sintaxe

$\%$

$\%$ shepard(areia,argila),

$\%$

$\% \quad$ sendo que areia = fração de areia

$\% \quad$ argila $=$ fração de argila

$\%$

\% Schettini, 29 de julho de 1998

function shepard(areia,argila)

altura $=\left(1-0.5^{\wedge} 2\right)^{\wedge} 0.5$

for $\mathrm{i}=1$ :length(areia)

$y(i)=\operatorname{argila}(i)^{\star}$ altura;

$x(i)=1-\operatorname{areia}(i)-y(i)^{\star} \tan \left(30^{*} \mathrm{pi} / 180\right)$;

end

$\operatorname{plot}\left(x, y,{ }^{\prime * \prime}\right)$

\% desenha o triângulo externo

$\mathrm{x} 1=\left[\begin{array}{llll}0 & 0.5 & 1 & 0\end{array}\right] ; \mathrm{y} 1=\left[\begin{array}{l}0 \\ 0 \text { altura } 0\end{array}\right]$;

$\%$ desenha os limites dos extremos

$x 2=[1 / 4$ 1/8]; y2=[0 1/4*altura ];

$\mathrm{x} 3=\left[3 / 4^{*} \cos \left(60^{*} \mathrm{pi} / 180\right) 1-3 / 4^{*} \cos \left(60^{*} \mathrm{pi} / 180\right)\right]$;

$\mathrm{y} 3=\left[3 / 4^{*}\right.$ altura $3 / 4^{*}$ altura];

$\mathrm{x} 4=[7 / 83 / 4]$; y4=[1/4*altura 0$]$;

$\%$ desenha o triângulo interno

x5=[1/5*altura/tan(30* pi/180) $1 / 21-1 / 5^{*}$ altura/tan(30* $\left.\mathrm{pi} / 180\right)$

$1 / 5^{\star}$ altura/tan(30* $\left.\left.\mathrm{pi} / 180\right)\right]$;

y5=[1/5*altura $1 / 21 / 5^{\star}$ altura $1 / 5^{\star}$ altura $]$;

$\%$ desenha as linhas internas

$\mathrm{x} 6=\left[3 / 161 / 5^{\star}\right.$ altura/tan(30* $\left.\left.\mathrm{pi} / 180\right)\right]$;

y $6=\left[1 / 8^{*} \sin \left(60^{*} \mathrm{pi} / 180\right) 1 / 5^{\star}\right.$ altura $]$

$x 7=\left[4 / 5^{\star}\right.$ altura ${ }^{*} \cos \left(30^{*} \mathrm{pi} / 180\right)$ altura* $\left.\cos \left(30^{*} \mathrm{pi} / 180\right)\right]$;

y $7=\left[4 / 5^{\star}\right.$ altura* $\sin \left(30^{*} \mathrm{pi} / 180\right)$ altura* $\left.\sin \left(30^{*} \mathrm{pi} / 180\right)\right]$;

$\mathrm{x} 8=\left[1-3 / 161-1 / 5^{\star}\right.$ altura/tan $\left.\left(30^{*} \mathrm{pi} / 180\right)\right]$;

y8 $=\left[1 / 8^{*} \sin \left(60^{*} \mathrm{pi} / 180\right) 1 / 5^{*}\right.$ altura $]$

$\mathrm{x} 9=\left[1-4 / 5^{*}\right.$ altura ${ }^{*} \cos \left(30^{*} \mathrm{pi} / 180\right) 1$-altura* $\left.\cos \left(30^{*} \mathrm{pi} / 180\right)\right]$;

y $9=\left[4 / 5^{\star}\right.$ altura ${ }^{\star} \sin \left(30^{*} \mathrm{pi} / 180\right)$ altura* $\left.\sin \left(30^{*} \mathrm{pi} / 180\right)\right]$;

$\mathrm{x} 10=[1 / 21 / 2] ; \mathrm{y} 10=[0$ altura*0.2];

$\mathrm{x} 11=[1 / 21 / 2] ; \mathrm{y} 11=[1 / 2$ altura*0.75];

hold on; box off; axis equal; axis off plot(x1,y1); plot(x2,y2);plot(x3,y3);plot(x4,y4); $\operatorname{plot}(x 5, y 5)$;

plot(x6,y6,':');plot(x7,y7,':');plot(x8,y8,':');plot(x9,y9,':'); 